\title{
On the Role of pre-treatment of Aluminum Substrate on Deposition of Cerium Based Conversion Layers and Their Corrosion-Protective Ability
}

\author{
Reni Andreeva ${ }^{1}$, Emilia Stoyanova $^{1}$, Aleksandar Tsanev ${ }^{2}$, Maria Datcheva $^{3}$, Dimitar Stoychev $^{1, *}$ \\ ${ }^{1}$ Institute of Physical Chemistry "Rostislaw Kaischew”, Bulgarian Academy of Sciences, Acad. G. \\ Bonchev str., Bl. 11, 1113 Sofia, Bulgaria \\ ${ }^{2}$ Institute of General and Inorganic chemistry, Bulgarian Academy of Sciences, Acad. G.Bonchev str., \\ B1. 11, 1113 Sofia, Bulgaria \\ ${ }^{3}$ Institute of Mechanics, Bulgarian Academy of Sciences, Acad. G.Bonchev str., Bl. 4, 1113 Sofia, \\ Bulgaria \\ *E-mail: stoychev@ipc.bas.bg
}

doi: $10.20964 / 2018.06 .71$

Received: 7 February 2018 / Accepted: 11 April 2018 / Published: 10 May 2018

We've investigated the effect of preliminary Al substrate treatment on the deposition and corrosionprotection ability of thin, conversion cerium oxide layers formed in solutions containing $\mathrm{Ce}^{3+}$ and $\mathrm{Cu}^{2+}$ ions. The cerium oxide layers and their corrosion protection behaviour were investigated by SEM, EDS, XPS, and model polarization E-lg i and I-t chronoamperometric curves. We report on the structure, morphology, chemical composition and the state of the elements in the conversion layers, as well as the thickness and distribution of the elements up to the „conversion layer"/"aluminium substrate" interphase boundary. The preliminary treatment of the Al substrate, as well as the presence of $\mathrm{Cu}^{2+}$, both substantially influence the thickness, composition and protective ability of the formed ceria and alumina mixed conversion layers. All these features are related to changes in the ratio of the formed $\mathrm{AlOOH}\left(\sim \mathrm{Al}_{2} \mathrm{O}_{3} \cdot \mathrm{H}_{2} \mathrm{O}\right), \mathrm{Ce}(\mathrm{OH})_{3}\left(\sim \mathrm{Ce}_{2} \mathrm{O}_{3}\right)$ and $\mathrm{Ce}(\mathrm{OH})_{4}\left(\sim \mathrm{CeO}_{2}\right)$ on the modified $\mathrm{Al}$ surface, which are affected by the preliminary treatment of the $\mathrm{Al}$ substrate and presence of $\mathrm{Cu}^{2+}$ ions in the immersion treatment solution based on $\mathrm{Ce}^{3+}$ ions.

Keywords: Aluminium, Pre-treatment, Conversion layers, Cerium oxides, Corrosion protection

\section{FULL TEXT}

(C) 2018 The Authors. Published by ESG (www.electrochemsci.org). This article is an open access article distributed under the terms and conditions of the Creative Commons Attribution license (http://creativecommons.org/licenses/by/4.0/). 